\title{
Space Environment Testing of Photovoltaic Array Systems at NASA's Marshall Space Flight Center
}

\author{
Todd A. Schneider ${ }^{1}$, Jason A. Vaughn ${ }^{1}$, Kenneth H. Wright Jr. ${ }^{2}$, and Brandon S. Phillips ${ }^{3}$ \\ ${ }^{1}$ NASA/MSFC, Huntsville, AL, 35812, USA, ${ }^{2}$ University of Alabama Huntsville, Huntsville, AL 35899, \\ USA, ${ }^{3}$ Aerodyne Inc., Huntsville, AL, 35802, USA
}

\begin{abstract}
To successfully operate a photovoltaic (PV) array system in space requires planning and testing to account for the effects of the space environment. It is critical to understand space environment interactions not only on the PV components, but also the array substrate materials, wiring harnesses, connectors, and protection circuitry (e.g. blocking diodes). Key elements of the space environment which must be accounted for in a PV system design include: Solar Photon Radiation, Charged Particle Radiation, Plasma, and Thermal Cycling. While solar photon radiation is central to generating power in PV systems, the complete spectrum includes short wavelength ultraviolet components, which photo-ionize materials, as well as long wavelength infrared which heat materials. High energy electron radiation has been demonstrated to significantly reduce the output power of III-V type PV cells; and proton radiation damages material surfaces - often impacting coverglasses and antireflective coatings. Plasma environments influence electrostatic charging of PV array materials, and must be understood to ensure that long duration arcs do not form and potentially destroy PV cells. Thermal cycling impacts all components on a PV array by inducing stresses due to thermal expansion and contraction. Given such demanding environments, and the complexity of structures and materials that form a PV array system, mission success can only be ensured through realistic testing in the laboratory. NASA's Marshall Space Flight Center has developed a broad space environment test capability to allow PV array designers and manufacturers to verify their system's integrity and avoid costly on-orbit failures. The Marshall Space Flight Center test capabilities are available to government, commercial, and university customers. Test solutions are tailored to meet the customer's needs, and can include performance assessments, such as flash testing in the case of PV cells.
\end{abstract}

Index Terms - space environment, photovoltaic test and evaluation, photovoltaic array

\section{INTRODUCTION}

CubeSats, Communication Satellites, and Outer Planet Science Satellites all share one thing in common: Mission success depends on maintaining power in the harsh space environment.

For a vast majority of satellites, spacecraft power is sourced by a photovoltaic (PV) array system. Built around PV cells, the array systems also include wiring, substrates, connectors, and protection diodes. Each of these components must function properly throughout the mission in order for power production to remain at nominal levels. Failure of even one component can lead to a crippling loss of power.
To help ensure PV array systems do not suffer failures onorbit due to the space environment, NASA's Marshall Space Flight Center (MSFC) has developed a wide ranging test and evaluation capability. Key elements of this capability include:

\section{Testing}

- Ultraviolet (UV) Exposure

- Charged Particle Radiation (Electron and Proton)

- Thermal Cycling

- Plasma and Beam Environments

\section{Evaluation}

- Electrostatic Discharge (ESD) Screening

- Optical Inspection and Measurement

- PV Power Output including Large Area Pulsed Solar Simulator (LAPSS) measurements

This paper will describe the elements of the space environment which particularly impact PV array systems. MSFC test capabilities will be described to show how the relevant space environments can be applied to PV array systems in the laboratory. A discussion of MSFC evaluation capabilities will also be provided. The sample evaluation capabilities offer test engineers a means to quantify the effects of the space environment on their PV array system or component. Finally, examples will be shown of the effects of the space environment on actual PV array materials tested at MSFC.

\section{THE SPACE ENVIRONMENT}

The space environment varies dramatically across our solar system. The following environments represent a wide crosssection in terms of the environment characteristics; however they constitute the most popular environments with respect to qualification testing needs and number of spacecraft deployed to those regions of space.

\section{A. Geosynchronous Earth Orbit (GEO)}

The most common orbit for communication satellites, some of the key features include:

- A low density plasma environment with streaming electrons in the $1 \mathrm{keV}$ to $30 \mathrm{keV}$ range

- Long thermal cycle times

- Solar intensity of one sun ( 1 sun $=140$ milli-watts $\left./ \mathrm{cm}^{2}\right)$

- High energy radiation events - solar storm events 


\section{B. Low Earth Orbit (LEO)}

Commonly occupied by Earth-observing satellites, manned missions, CubeSats, and NanoSats, LEO is characterized by:

- High density Oxygen plasma with up to $10^{6}$ particles $/ \mathrm{cm}^{3}$

- 90 minute thermal cycle times

- Solar intensity of one sun (1 sun $=140$ milli-watts $\left./ \mathrm{cm}^{2}\right)$

- Neutral atomic Oxygen

\section{Solar Wind Environments}

This is a broad environment category that refers to regions well outside of Earth orbit, such as interplanetary environments and lunar orbits. The solar wind is a continuous stream of charged particles generated by the Sun. The solar wind environments can be generally characterized as:

- Low density plasma with only 6-10 particles $/ \mathrm{cm}^{3}$

- Minimal thermal cycles

- Solar intensities ranging from a fraction of one sun for outer planets, to several hundred suns for missions inside of Mercury's orbit $\left(1\right.$ sun $=140$ milli-watts $\left./ \mathrm{cm}^{2}\right)$

\section{TEST CAPABILITIES}

MSFC space environment test capabilities are far ranging. They cover from the solar corona to the outer planets, with a particular focus on Earth orbit environments. Led by experienced personnel in the Environmental Effects Branch, test programs are tailored to the customer's needs, and can range from a fully integrated test program that uses all of the test systems described below, to focused tests that employ a single capability.

\section{A. Ultraviolet (UV) Radiation}

MSFC's Environmental Effects Branch has developed an ultraviolet (UV) radiation capability to cover both materials and PV array tests. Five different UV test facilities comprise the capability, and provide $R \& D$ engineers with a means to screen new materials, or for systems engineers to qualify solar arrays in compliance with the AIAA standard [1].

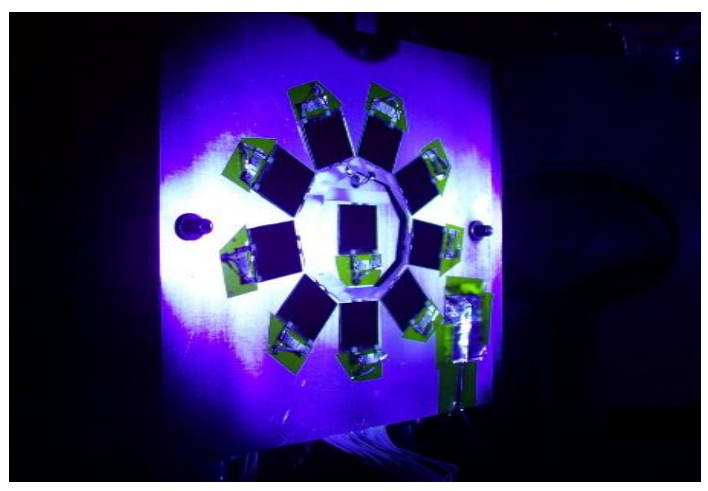

Fig. 1. Solar cell samples undergoing combined ultraviolet radiation exposure tests (VUV and NUV).
The facilities' active UV beam spot size range from $10 \mathrm{~cm}$ to $60 \mathrm{~cm}$ diameter. Two of the five test facilities have the additional capability of simultaneously combing vacuum ultraviolet radiation (VUV) (115 nm to $200 \mathrm{~nm})$ with near ultraviolet radiation (NUV) $(200 \mathrm{~nm}$ to $400 \mathrm{~nm})$. The UV facilities are capable of long duration run times - as demonstrated by the successful completion of a materials test which ran in excess of 8,000 equivalent sun hours.

All UV facilities use oil-free pumping systems to reduce contamination in the vacuum systems. The vacuum systems operate at high vacuum with pressures as low as $2 \times 10^{-7}$ Torr. Each system can be configured with a cold plate to control sample temperature and avoid complications due to overheating.

The UV sources in-use at MSFC are described in Table I. It is common to combine sources on a single vacuum system to achieve a UV environment that is close to on-orbit conditions. Fig. 1 shows a typical test setup in which solar cell samples are being exposed simultaneously to NUV and VUV radiation.

\section{TABLE I}

UV SOURCES OPERATED BY MSFC'S

ENVIRONMENTAL EFFECTS BRANCH

\begin{tabular}{|c|l|l|}
\hline Source & $\begin{array}{c}\text { Wavelength } \\
\text { Range }\end{array}$ & \multicolumn{1}{c|}{ Features } \\
\hline $\begin{array}{c}\text { Spectrolab } \\
\text { X-25 }\end{array}$ & $250-3000 \mathrm{~nm}$ & $\begin{array}{l}\text { Full solar spectrum from } \\
\text { NUV through short } \\
\text { wavelength IR. Filters } \\
\text { included to better match } \\
\text { the AM0 spectrum }\end{array}$ \\
\hline $\begin{array}{c}\text { Deuterium } \\
\text { Lamp }\end{array}$ & $115-200 \mathrm{~nm}$ & $\begin{array}{l}\text { Vacuum Ultraviolet } \\
\text { (VUV); Capable of } 2-4 \\
\text { equivalent VUV suns } \\
\text { intensity }\end{array}$ \\
\hline Enhanced & \multirow{2}{*}{$230-580 \mathrm{~nm}$} & $\begin{array}{l}\text { Provides strong NUV } \\
\text { radiation without } \\
\text { heating the sample (IR } \\
\text { wavelengths are } \\
\text { filtered-out). Intensities } \\
\text { as high as 4 - 5 } \\
\text { equivalent NUV suns } \\
\text { are achievable. }\end{array}$ \\
\hline HISET & $250-3000 \mathrm{~nm}$ & $\begin{array}{l}\text { Capable of extremely } \\
\text { high intensities: } 500 \\
\text { equivalent suns over a } \\
10 \text { cm spot. } \\
\text { Configurable to produce } \\
1 \text { sun intensity over a } \\
\text { large (60 cm diameter) } \\
\text { spot size. Full solar } \\
\text { spectrum coverage. }\end{array}$ \\
\hline & &
\end{tabular}

As indicated in Table I, many of the UV sources are capable of delivering intensities greater than 1 sun at the sample location. Operation at higher intensity levels can significantly reduce the overall sample test time - which reduces costs and increases schedule margin. 


\section{B. Charged Particle Radiation}

It is well known that charged particle radiation degrades the performance of photovoltaic devices [2] - [4]. For spacecraft operating in environments subjected to high energy electron and proton radiation, the degradation of PV cells translates to reduced power levels over the mission lifetime. Testing PV cells, and PV array coupons, is therefore important to determine End-of-Life (EOL) power margins. The charged particle radiation facility at MSFC can be used to qualify PV array systems according to accepted standards [5] or to simply gauge the susceptibility of a new array system to damage as a result of radiation. Screening for radiation effects applies not only to PV components, but to materials (e.g. polymers and adhesives) as well as subsystems (e.g. wiring harnesses and diode modules).

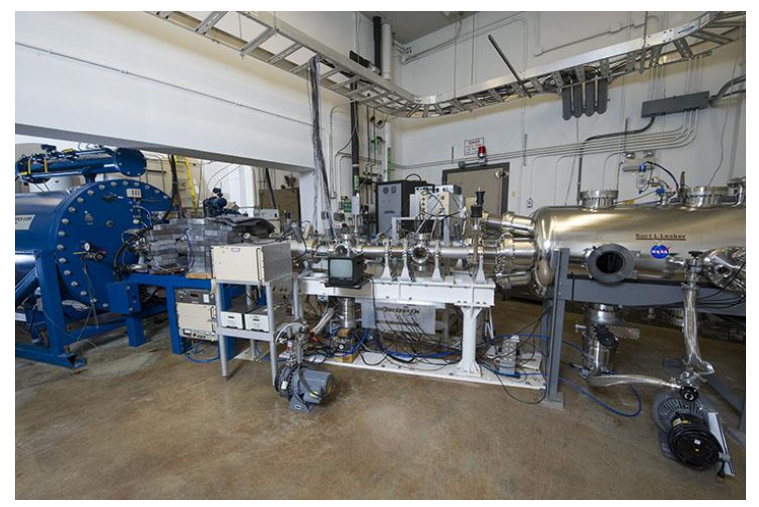

Fig. 2. The High Energy Charged Particle Radiation facility. The electron accelerator is visible on the left side (blue chamber) and the sample chamber is visible on the right side (silver chamber). The proton accelerator is not visible in this picture.

The Environmental Effects Branch operates two linear accelerators to provide high energy charged particle radiation. The accelerators are connected, via vacuum beam lines, to a cylindrical sample chamber with $0.8 \mathrm{~m}$ diameter. Fig. 2 is a picture of the MSFC charged particle radiation facility showing the sample chamber (silver colored chamber on the right) and one of the accelerators (blue device on the left). Details about the accelerators are provided in Table II.

TABLE II

High ENERgy CHARGED PARTICLE RADIATION FACILITY SPECIFICATIONS

\begin{tabular}{|c|c|c|c|}
\hline Device & $\begin{array}{c}\text { Energy } \\
\text { Range } \\
\text { (MeV) }\end{array}$ & $\begin{array}{c}\text { Flux } \\
\text { Range } \\
\left(\mathbf{n A} / \mathbf{c m}^{2}\right)\end{array}$ & $\begin{array}{c}\text { Maximum } \\
\text { Beam Diameter } \\
\text { (cm) }\end{array}$ \\
\hline $\begin{array}{c}\text { Electron } \\
\text { Accelerator }\end{array}$ & $0.2-2.5$ & $0.03-10$ & 40 \\
\hline $\begin{array}{c}\text { Proton } \\
\text { Accelerator }\end{array}$ & $0.04-0.7$ & $1-10$ & 40 \\
\hline
\end{tabular}

The accelerators can be operated individually or at the same time. Beam energy and flux levels can be adjusted to meet the customer's requirements, as well as minimize the total test time required to achieve full fluence. Prior to initiating a radiation exposure test, flux levels at the sample plane are confirmed using a Faraday cup, and uniformity is measured using optical analysis of specialized polymer films. Beam uniformity levels as high as $90 \%$ are routinely achieved.

\section{Thermal Cycles}

Spacecraft in Earth orbit are subjected to temperature extremes ranging from $+150 \mathrm{C}$ when fully exposed to the Sun, to $-180 \mathrm{C}$ when in eclipse. The continual cycling of temperatures on spacecraft materials and components stresses systems due to thermal expansion and contraction. When combined with other space environment effects, such as radiation hardening, thermal cycles can lead to cracked insulators, broken wires, and severely compromised components. Thermal cycle testing is, therefore, an essential part of any qualification program for spacecraft materials and systems - particularly PV array systems.

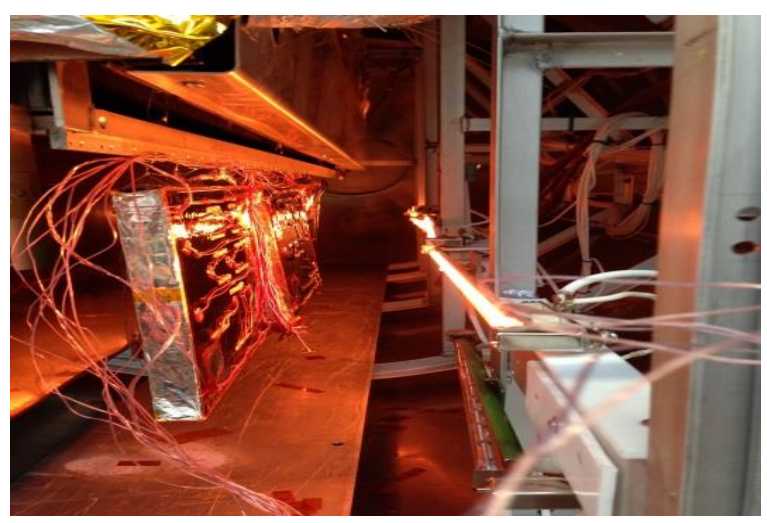

Fig. 3. Solar array wire coupons being heated in the V3 thermal cycle chamber. Samples are translated between the heated zone at the bottom of the chamber and the cold zone at the top of the chamber.

MSFC's Environmental Test Facility has developed multiple thermal cycle chambers which are capable of testing small material samples to full size spacecraft modules. Starting in 2008, a collaborative effort was launched which created a system dedicated to testing PV array coupons (including PV cell and PV wiring harness coupons). The "V3" system is a vacuum based thermal cycle chamber capable of cycling in the range of $+150 \mathrm{C}$ to $-180 \mathrm{C}$. The system is a dual zone system that translates samples between a liquid nitrogen cooled zone at the top of the chamber, to a hot zone created by infrared heating lamps at the bottom of the chamber. The programmable translation system allows for the creation of customized thermal profiles, including set dwell times at the temperature extremes. Fig. 3 is a picture of the interior of the V3 system which shows solar array wire coupons being heated by the infrared lamps. The cryogenic "cold box" is visible just above the top of the coupons. 
With computer control and monitoring of the V3 thermal cycle chamber, continuous operation 24 hours/day and 7 days/week is routine, which helps reduce the total number of test days required to achieve a thermal cycle requirement. The V3 system has demonstrated performance - with thousands of logged cycles for a GEO satellite system [6].

\section{Plasma and Low Energy Beam Environments}

In addition to the charged particle and UV radiation sources, the MSFC Environmental Effects Branch maintains a full complement of plasma and beam sources, which can be deployed in a wide variety of combinations to meet the needs of the most demanding missions. Table III presents the key features of these sources.

TABLE III

PlaSMA AND BEAM SOURCE CAPABILITIES

\begin{tabular}{|l|l|}
\hline Source & Characteristics \\
\hline $\begin{array}{l}\text { LEO } \\
\text { Plasma }\end{array}$ & $\begin{array}{l}0.1 \mathrm{eV} \text { Electron Temperature, } \\
5 \mathrm{eV} \text { Drifting lons }\end{array}$ \\
\hline $\begin{array}{l}\text { Thruster } \\
\text { Plasma }\end{array}$ & $250-1,000 \mathrm{eV}$ Xenon lons \\
\hline $\begin{array}{l}\text { Hollow Cathode } \\
\text { Plasma }\end{array}$ & $\begin{array}{l}0.5 \mathrm{eV} \text { Electron Temperature, } \\
\sim 10^{6} \text { particles } / \mathrm{cm}^{3} \text { Density }\end{array}$ \\
\hline $\begin{array}{l}\text { Broad Beam } \\
\text { lons }\end{array}$ & $150 \mathrm{eV}$ to $8 \mathrm{keV}$ \\
\hline $\begin{array}{l}\text { Narrow Beam } \\
\text { Protons }\end{array}$ & $500 \mathrm{eV}$ to $10 \mathrm{keV}$ \\
\hline $\begin{array}{l}\text { Broad Beam } \\
\text { Electrons }\end{array}$ & $90 \mathrm{eV}$ to $100 \mathrm{keV}$ \\
\hline $\begin{array}{l}\text { Neutral Atomic } \\
\text { Oxygen }\end{array}$ & $5 \mathrm{eV}, 5 \times 10^{15} \mathrm{atoms} / \mathrm{cm}^{2} / \mathrm{sec}$ \\
\hline
\end{tabular}

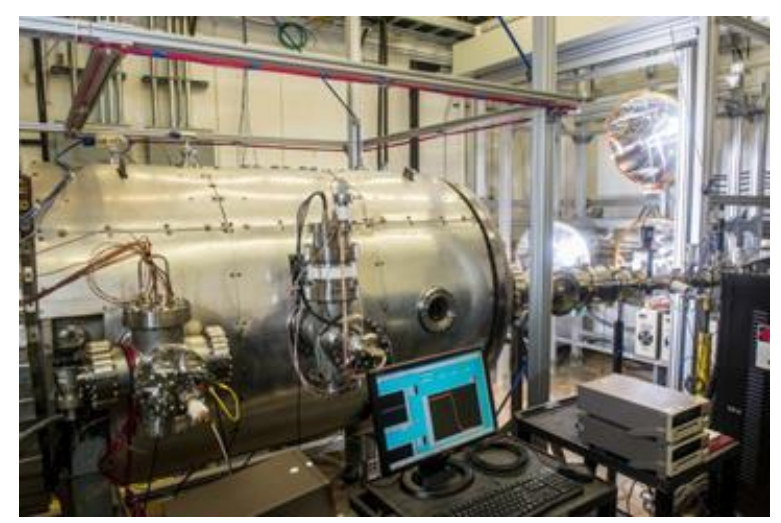

Fig. 4. HISET facility at MSFC. The facility is equipped with both broad beam and narrow beam electron and ion sources, as well as high intensity solar simulator lamps.

\section{SAMPLE EVALUATION CAPABILITIES}

In order to quantify the effects of the space environment on a given sample or system, MSFC has developed a number of measurement and evaluation capabilities.

\section{A. Electrostatic Discharge (ESD) Screening}

As plasma and charged particle environments exist throughout the solar system, spacecraft charging is ubiquitous. The magnitude and impact of spacecraft charging is dependent on the mission environments and spacecraft design features. In the case of spacecraft employing PV arrays, the plasma and charged particle radiation environments can cause electrostatic discharges (or arcs) to form on the PV array and potentially damage cells or strings of cells. Fig. 5 shows the formation of two ESD arc sites on a test coupon in the laboratory under GEO environment conditions [6].

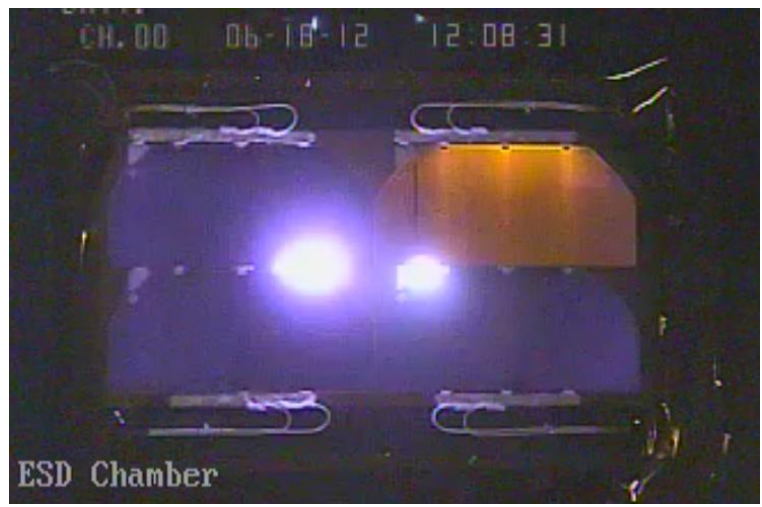

Fig. 5. ESD arc site formation on a 4-cell PV array coupon. The coupon was tested under GEO environment conditions.

Within a given PV array system design, many factors can contribute to the likelihood of ESD formation, including cellto-cell spacing, interconnect and bus tab configurations, string voltage and current levels, etc. Accurately predicting the formation of ESD on an array system is extremely difficult. Therefore, the best practice is to perform ESD screening tests.

MSFC's Environmental Effects Branch has conducted hundreds of ESD screening tests using a broad range test capability they first developed in 2002 to evaluate high voltage array designs [7]. The ESD test capability has been continually updated as the state-of-the-art has changed over time [8]. Having helped to develop an international test standard, the MSFC ESD Test system is capable of performing ESD screening tests compliant with the ISO-11221 standard [9].

Two key parameters are fundamental to the MSFC ESD Screening Tests:

1) Arc Inception Voltage Determination - This test measures the charging conditions in which an ESD arc forms. The formation of a "primary arc" does not constitute a threat to damage a PV component; however it can be a catalyst for formation of a severe discharge event.

2) Secondary Arc Susceptibility - Determines if a long duration secondary arc is likely to form on the PV 
array (cells or wiring). The formation of a sustained arc poses a threat to PV system operation, as whole strings of cells or bus circuits can be damaged thereby significantly reducing power production.

The MSFC ESD Test capability can be used to screen PV systems in a wide variety of environments including LEO, GEO, radiation belt, and even electric propulsion thruster plume. Vacuum chamber size limits test samples to coupons on the order of $60 \mathrm{~cm} \times 60 \mathrm{~cm}$. However, multi-string coupons are accommodated (in keeping with AIAA test standard S-111-2005) and external test circuitry is in place to compensate for differences in capacitance between a full flight panel and a test coupon. The MSFC system is also configured to perform ESD tests with sample temperatures in the range of $+100 \mathrm{C}$ to $-70 \mathrm{C}$.

\section{B. Photovoltaic Power Output}

The MSFC Power System Test Facility provides the capability to illuminate solar cells and panels as large as 1.1 $\mathrm{m}^{2}\left(12 \mathrm{ft}^{2}\right)$. This facility is equipped with a Spectrolab, largearea pulsed solar simulator (LAPSS) that contains its own data acquisition and control system. The MSFC LAPSS is capable of illuminating the target to the air-mass-zero (AM0) intensity level of 140 milli-watts $/ \mathrm{cm}^{2}$, or 1 sun, with an overall uniformity within 3\%. The facility's Multi-Junction LAPSS Lamp-house provides control of the spectral distribution needed for testing the state-of-the-art multi-junction solar cells. The integrated data system outputs current-voltage (I-V) curves which provide critical performance information for either individual solar cells or strings of cells.

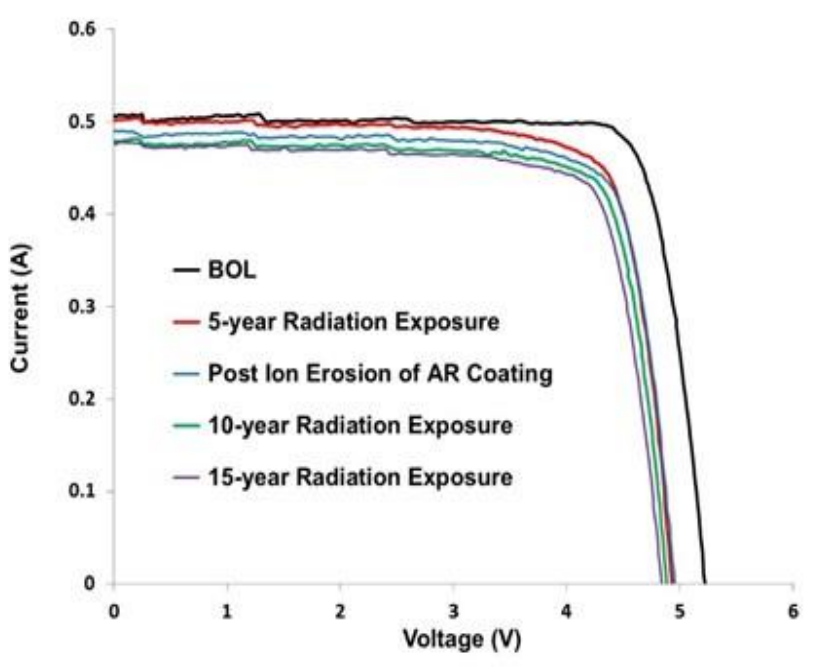

Fig. 6. Current versus Voltage (I-V) curves generated using the LAPSS system at MSFC. The test sample was a 2-cell string that was part of a fully integrated PV array coupon.

In addition to the LAPSS system, MSFC also has the capacity to make in-situ measurements of PV arrays or PV cell samples while they are undergoing UV, Radiation, or ESD testing. Using Source Measurement Units (SMU), the team at MSFC has experience making 4-wire measurements to produce I-V curves, including Dark I-V curves.

\section{Optical Inspection and Measurement}

Given that space environment exposures of PV array coupons and material samples often results in changes in optical properties, the Environmental Effects Branch utilizes the following techniques to document the changes:

- Optical Microscopy - Leica Digital Microscope - up to 30X magnification; annotated high resolution TIFF images

- Hemispherical Emissivity Measurement - AZ Technology Temp 2000 - integrated emissivity

- Solar Absorptance - AZ Technology LPSR 3000 outputs curve over the range of $250 \mathrm{~nm}$ to $2800 \mathrm{~nm}$

\section{TEST RESULTS}

The MSFC team has tested PV array systems in laboratory simulated space environments for over ten years. A particular focus for the MSFC team has been materials and components associated with commercial GEO communication satellites. Below are a few examples of PV array materials exposures in MSFC facilities [6].

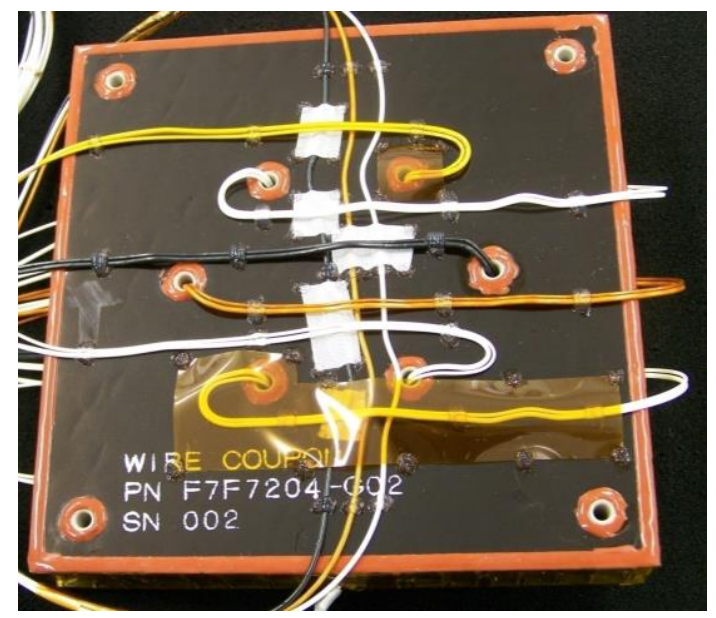

Fig. 7. Solar array wire coupon at Beginning of Life (BOL). The insulated wires are characteristic of those used on the sun-facing side of the array

In Fig. 6 the effect of high energy charged particle radiation on a string of PV cells can be seen as a change in the current versus voltage (I-V) curve. The radiation levels were applied in 5-year on-orbit equivalent exposures. There is a marked, but predictable, change in performance after the 5-year 
exposure due to a combination of radiation and ion erosion of the anti-reflective (AR) coating on the cells' coverglass. Additional degradation is observed after the 10-year and 15year radiation exposures [10].

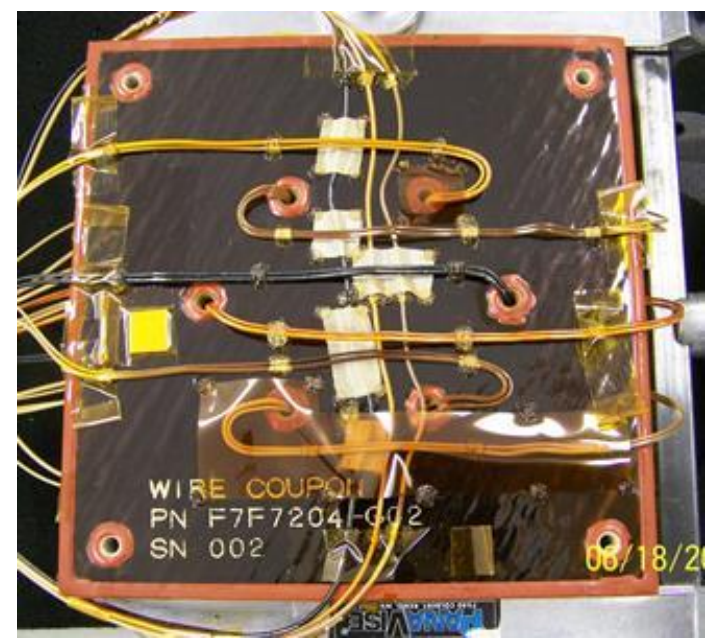

Fig. 8. Solar array wire coupon after 15 year equivalent of on-orbit UV exposure. Notice the darkening of the wire insulation compared to the BOL coupon in Fig. 6.

Comparing Fig. 7 with Fig. 8, one can see the effect of UV radiation on the white wires as they turn to a yellow/brown color. The samples are composed of insulated wires on a typical Kapton-covered rigid substrate. The samples are representative of a sun-facing PV array wiring harness used on a GEO satellite to transfer power from the PV array strings to the satellite power distribution system.

In Fig. 9, cracks have developed in the wire insulation as a result of radiation hardening combined with thermal cycling.

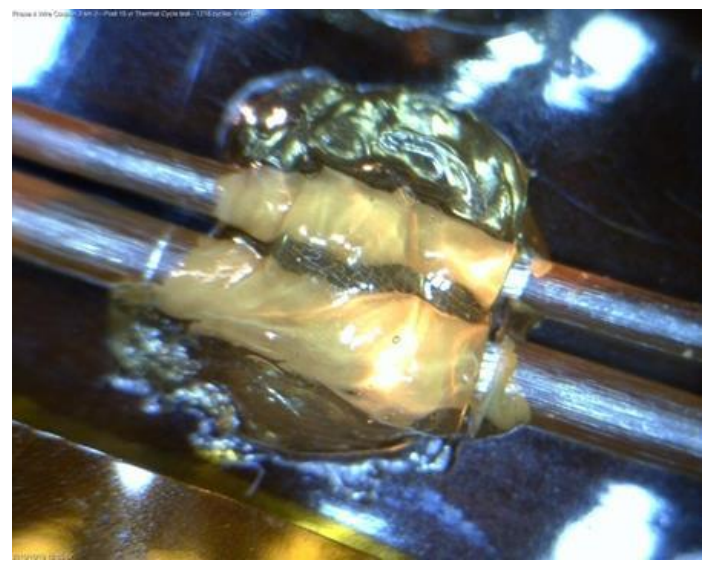

Fig. 9. Close-up of insulated wires on a solar array test coupon. Cracks have formed in the wire insulation close to a RTV spot bond. The cracks formed after being subjected to 15 year equivalent GEO environment exposure.

\section{CONCLUSION}

The space environment is a demanding environment and can take its toll on PV array system materials and components. On-orbit degradation of these components can, in some cases, jeopardize spacecraft power production. To avoid on-orbit failures, it is best to test PV array systems in realistic space environments recreated in the laboratory. NASA's Marshall Space Flight Center has developed a broad range of space environment test capabilities to help customers validate the performance of their PV systems. Complementary to the test capability is an evaluation capability which allows for rapid feedback on how the space environment is impacting the PV array materials - including the PV cells.

\section{REFERENCES}

[1] American Institute of Aeronautics and Astronautics (AIAA) Standard S-112-2005 "Qualification and Quality Requirements for Space Solar Panels" (ISBN 1-56347-787-4)

[2] B. E. Anspaugh, GaAs Solar Cell Radiation Handbook, JPL Publication 96-9, 1996.

[3] D. C. Marvin, "Assessment of Multijunction Solar Cell Performance in Radiation Environments", Aerospace Report No. TOR-2000(1210)-1, 2000.

[4] Sharps, P.R., Thang, C.H., Martin, P.A., Hou, H.Q., "Proton and electron radiation analysis of GaInP2/GaAs solar cells", Conference Record of the Twenty-Eighth IEEE Photovoltaics Specialists Conference, 2000, DOI: 10.1109/PVSC.2000.916078, Publication Year: 2000 , Page(s): 1098-1101

[5] American Institute of Aeronautics and Astronautics (AIAA) Standard S-111-2005 "Qualification and Quality Requirements for Space Solar Cells" (ISBN 1-56347-785-8)

[6] Wong, F.K. ; Gardiner, G. ; Bao Hoang ; Redick, T. ; Gahart, R.L. ; Wright, K.H. ; Vaughn, J.A. ; Schneider, T.A., "Electrostatic Discharge Tests on Solar Array Wire Coupons Subjected to Simulated Space Environment Aging," IEEE Transactions on Plasma Sciences, vol. 41, no. 12, pp. 33593369, 2013.

[7] Todd A. Schneider, I. G. Mikellides, G. A. Jongeward, T. Peterson, T. W. Kerslake, D. Snyder, and D. Ferguson, "Solar Arrays for Direct-Drive Electric Propulsion: Arcing at High Voltages", Journal of Spacecraft and Rockets Vol. 42, No. 3, May-June 2005, pp. 543-549

[8] K. H. Wright, Jr., T. A. Schneider, J. A. Vaughn, B. Hoang, V. V. Funderburk, F. Wong, and G. Gardiner, Electrostatic Discharge Testing of Multi-Junction Solar Array Coupons after Combined Space Environmental Exposures, IEEE-Trans. Plasma Sci., 40, No. 2, 334, 2012. DOI: 10.1109/TPS.2011.2174447.

[9] ISO-11221, "Space systems - Space solar panels - Spacecraft charging induced electrostatic discharge test methods," 2011

[10] B. Hoang, V. V. Funderburk, F. Wong, G. Gardiner, K. H. Wright, Jr., T. A. Schneider, and J. A. Vaughn, ESD Characteristics of Solar Array Coupons after Simulated Combined Space Environmental Exposures, Proceedings of the 28th European Photovoltaic Solar Energy Conference and Exhibition, Session 1BO.12.4, Paris, France, 30 Sep-04 Oct, 2013 